\title{
The role of feedback and social presence in an online peer coaching program for student teachers
}

\author{
Marieke Thurlings \\ Eindhoven School of Education, Technical University Eindhoven, the Netherlands
}

Marjan Vermeulen

Faculty Psychology and Educational Sciences, Open Universiteit Nederland, the Netherlands KPC-group, 's-Hertogenbosch, the Netherlands

\section{Theo Bastiaens}

Faculty Psychology and Educational Sciences, Open Universiteit Nederland, the Netherlands FernUniversität, Hagen, Germany

\section{Sjef Stijnen}

Faculty Psychology and Educational Sciences, Open Universiteit Nederland, the Netherlands

Feedback is essential in any kind of learning. This study focused on feedback in online learning and conceptualized feedback as a social interaction process. Online learning rests on social interaction, which is affected by feelings of social presence. Therefore, we investigated received and perceived online feedback, and the coherence between them. In addition, we studied the influence of social presence on feedback processes. Sixteen Dutch student teachers, who followed a 1 year customized postgraduate teacher education course, engaged in an online peer coaching program using Skype. Data could be collected from 8 different participants and 966 feedback utterances were analysed. In order to determine the quality of this received feedback, an observational instrument was used. In addition, questionnaires were filled in that addressed student teachers' feedback perceptions and feelings of social presence. Findings showed that participants with higher feedback perceptions received more effective observed feedback than participants with lower perceptions. Feelings of social presence affected perceived and observed feedback, however the social presence items need further validation. This study has practical implications for providing effective online feedback as well as providing a more holistic view on the processes of feedback among teachers.

\section{Overview of our previous work}

The study described in this article is the last in a series undertaken as part of a research project. The research project aimed to provide more insights into the feedback processes among teachers and consisted of a literature review and several empirical studies. The literature review's (Thurlings, Vermeulen, Bastiaens \& Stijnen, 2013) aim was to update Scheeler, Ruhl and McAfee's (2004) findings. Scheeler et al. (2004) were the first, to our knowledge, who reviewed literature on feedback to teachers. They concluded that:

Despite the obvious limitations, the literature clearly supports three general conclusions that should be adopted into practice: (a) feedback is better than no feedback, (b) immediate feedback is better than delayed feedback, and (c) feedback that is immediate, specific, positive, and corrective holds the most promise for bringing about lasting change in teaching behaviour. (p. 68)

Moreover, they made a plea for future research on the subject of feedback among teachers, which indeed was followed by many researchers. In our literature review, we showed that feedback for teachers should be provided in (peer) coaching settings. In addition, feedback itself should be "task and/or goal-directed, focused on the learning process, specific, in time and frequent, positive, unbiased, non judging, constructive, hold elaborations and/or justifications, and encouraging dialogue" (Thurlings et al., 2013, p. 12). 
Based on these indicators, we then developed our observational instrument that allowed us to determine the quality of feedback provided by teachers. This observational instrument was called Teacher Feedback Observation Scheme (TFOS) and was piloted in a study by Thurlings, Vermeulen, Kreijns, Bastiaens and Stijnen (2012). Because of the preliminary findings of this pilot study and our experiences with the instrument, we adapted it in two ways. As well as clarifying some elements, TFOS was expanded with a questionnaire that sought teachers' perceptions of the received feedback. This adapted observational instrument was used in two following studies. In the first study (Thurlings, Vermeulen, Bastiaens \& Stijnen, 2012), 12 primary school teachers participated in a face-to-face peer coaching program (this program is explained in the next section). In the second study, 16 student teachers participated in the same peer coaching program, however, the program was implemented in an online synchronous learning environment. This empirical study is the last in the research project and is discussed in this article.

\section{The peer coaching program}

In all of the empirical studies, the same peer coaching program was implemented. This program is called the Video Intervision Peer (VIP) coaching program (Jeninga, 2003). The program aims to guide teachers in improving their own teaching behaviours, for instance, being more consistent in applying classroom rules. The peer coaching program has five pillars: reciprocal peer coaching, videotaped lessons, solutionfocused thinking, a cyclic workflow, and a process supervisor. The cyclic workflow holds four main steps: a) teachers videotape an aspect of their teaching behaviour, which they wish to improve, b) the teachers and process supervisor meet in the peer group, view and discuss the video, and by using solutionfocused thinking the peer coaches support the coached teacher to formulate goals and accompanying actions, c) the teachers try out their formulated actions and videotape this changed teaching behaviour, and d) the peer group meets again, views the video with changed behaviour and evaluates the changed behaviour. Based on this evaluation, the coached teachers decide whether they are satisfied with their changed behaviour or not. In the first case, a new goal and accompanying actions are formulated. In the second case, the goal and actions are reformulated and tried out again. The process supervisors act as chairperson and model solution-focused thinking. For each coached teacher, half an hour is reserved. In the case of a group of 3 teachers, the meeting takes about one and a half hours.

In this final study, the program was implemented in a synchronous online environment, namely Skype 4.1. This is a voice-over-IP program that allows phone calls over the internet. Skype facilitates conversations among 15 participants. Users only need a headset with a microphone.

Since the review of Scheeler et al. (2004), many studies were conducted on feedback to teachers. What is unique to ours is that we took on a larger research project than most other researchers. Based on an extended literature review, we constructed an observational instrument to actually investigate the feedback processes, which was lacking in most studies. Additionally, we explored participant's perceptions of feedback and in this study, also feelings of social presence, which is suggested to influence online learning processes (more will be explained later on this topic). As such, we undertook a more holistic study than most previous research.

\section{How we defined effective observed feedback in our studies}

Feedback has long been recognized as an effective learning tool for students (Hattie \& Timperley, 2007; Mory, 2003). However, research on feedback among (student) teachers is scarce (Scheeler et al., 2004) and therefore, our knowledge of how teachers can provide each other effective feedback in professional development activities is limited. Moreover, many studies on feedback to teachers examine teachers' perceptions of feedback or manipulated feedback characteristics to reveal their effectiveness. To further study feedback processes, we recommended applying observational techniques (Thurlings et al., 2013). In this section, we elaborate on the rationale for how we defined and described effective observed feedback.

In our research, feedback is defined as "information that allows for comparison between an actual and a desired outcome" (Mory, 2003, p. 746). This definition is applicable to non-instructive settings (Mory, 2003), such as the peer coaching program. Based on our literature review, we further described feedback in four dimensions that resonate with the indicators of effective feedback. The first dimension is goaldirectedness vs. non-goal/person-directedness and indicates whether feedback is directed at the task or goal at hand or not (e.g., Black \& Wiliam, 1998; Gibbs \& Simpson, 2004). It can also be directed at the 
receivers themselves. The second dimension is specific vs. general and deals with the question whether feedback is directed at a specific issue or whether it is more focused on general issues (e.g., Black \& Wiliam, 1998; Colasante, 2011; Scheeler et al., 2004). The third dimension is detailed vs. non-detailed and concerns whether feedback holds details or not (e.g., Gibbs \& Simpson, 2004; Scheeler et al., 2004). The fourth dimension is positive vs. neutral vs. negative and concerns whether feedback is expressed in a positive way (e.g., providing compliments), in a negative way (e.g., conveying slate or attacking the receivers), or in a neutral way (i.e., neither positive nor negative; e.g., Scheeler et al., 2004). Based on our literature review, we assumed that goal-directed, specific, and detailed feedback that is formulated in a neutral manner is more effective for learning than feedback that is person-directed, general, vague, and formulated either too positive or too negative (Thurlings et al., 2013; Thurlings, Vermeulen, Kreijns et al., 2012). These four dimensions are central in the observation instrument we used. These dimensions do not represent an either/or stance, but are continua.

In addition to these dimensions, we were interested in exploring how peer coaches can promote feedback receivers (i.e., the coached teacher) to become more goal-directed, more specific, more detailed, and neutral in their utterances, because we assumed that such feedback is more effective for learning. In exploring this issue, we distinguished feedback elements. These elements were based upon literature on coaching as well as the peer coaching program (Jackson \& McKergow, 2002; Jeninga, 2003; Smith \& Ragan, 1993; see also Thurlings, Vermeulen, Kreijns et al., 2012). Feedback elements were made operational, for instance as solution-focused questions, evocative questions, summarizing, judging, and providing examples from one's own experience.

In the feedback and peer coaching process, these elements can affect the feedback dimensions by either pushing the dimensions in the assumed effective directions (e.g., more goal-directed or more detailed), which means that the elements were effective, or by pushing the dimensions away from the assumed effective directions (e.g., more general or too positive or too negative), which means that the elements were not effective. Based on the peer coaching program and coaching literature, expectations of this effectiveness of the feedback elements were formulated. Seven elements were expected to be effective: open-ended, closed, solution-focused, and guiding questions, continuous questioning, summarizing, and acknowledging. Five elements were expected to be ineffective: evocative questions, hinting, judging, finishing coached teachers' sentences, and elaborating on one's own experience (Jackson \& McKergow, 2002; Jeninga, 2003; Smith \& Ragan, 1993; see also Thurlings, Vermeulen, Kreijns et al., 2012).

Effective observed feedback among teachers is thus the combination of the four dimensions (i.e., goaldirectedness, specificity, detailedness, and neutrality), the 12 feedback elements, and the influence of the elements on the dimensions.

\section{How we defined effective perceived feedback in our studies}

Perceptions of the learning environment are considered to influence learning (Entwistle, 1991). Many studies have explored the influence of such perceptions on learning and showed, for instance, that expectations of assessment influence students' approach to learning (Scouller, 1998). In addition, research in formative assessment has shown that feedback perceptions affect approaches to learning (Segers, Gijbels \& Thurlings, 2008).

Similarly, perceptions of feedback are likely to influence teachers' learning. Many studies have focused on perceptions of feedback in (student) teacher learning and several of these showed that in a variety of learning environments, student teachers who received feedback perceived this feedback as too positive and they preferred more constructive comments (e.g., Colasante, 2011; Yang \& Liu, 2004).

Based on a literature study, Gibbs and Simpson (2004) have described how feedback should be perceived such that it reinforces learning. They argued that, in quantitative terms, feedback should be provided frequently and should hold enough details. In qualitative terms, feedback should be focused at performances that learners can control. Furthermore, feedback should be appropriate for the tasks learners are performing and should consider learners' understanding of what they should be doing. If learners perceive feedback in alignment with these conditions, their learning is supposed to be reinforced (Gibbs \& Simpson, 2004). Moreover, Gibbs and Simpson (2004) argued that feedback should be received, attended to, and acted upon such that learning becomes optimal. 
Thus, feedback perceived as effective is feedback that is frequently provided, is focused on actions that teachers themselves initiate, is appropriate to learning goals, and has enough detail. Before we explain how we defined social presence in our studies, we will sketch the context and rationale for this concept: online learning.

\section{Online learning}

A major development in recent society is the digital revolution (Collins \& Halverson, 2009) and consequently, online learning has taken an enormous leap (Caballé, Daradoumis, Xhafa \& Juan, 2011). For instance, learners can join Virtual Action Learning or courses at Open Universities. Some major advantages of online learning are time and place independency and that learning can occur close to the workplace (e.g., King \& Dunham, 2005). In addition, online learning makes it possible to learn from and with external coaches. Finally, online learners can serve as a community of practice in which they share information, experiences, and knowledge (Wenger \& Snyder, 2000).

Research on feedback in online learning environments mostly focuses on written, asynchronous feedback in language and writing education (e.g., Hyland \& Hyland, 2006) or on student perceptions and preferences (e.g., Yang \& Liu, 2004). Others focus on the quality of online asynchronous discussions and how facilitators can support this process (e.g., Nandi, Hamilton, Chang \& Balbo, 2012). Moreover, "in the literature on computer-supported cooperative work, feedback itself is rarely mentioned" (Geister, Konradt \& Hertel, 2006, p. 465).

This digital revolution is also impacting teachers' professional development. Many online teacher networks have been established (e.g., Tsai, 2012) and many online teacher professional development programs have been developed and researched (e.g., Östlund, 2008). However, in online learning, social cues such as non-verbal behaviour are not always incorporated. The lack of these kinds of cues is believed to negate learning processes (Daft, Lengel \& Trevino, 1987). For instance, it is suggested that feelings of social presence influence online social learning (Tu \& McIsaac, 2002).

\section{How we defined social presence in our studies}

Social presence has its foundations in computer-mediated communication theories and is defined as "the degree of salience of the other person in the interaction and the consequent salience of the interpersonal relationships" (Short, Williams \& Christie, 1976, p. 65). Social presence can be considered from a technological stance or from a social stance (Kreijns, Kirschner, Jochems \& van Buuren, 2011). Short et al. (1976) supported the technological stance, which stated that the level of social presence is established by characteristics of the online environment, such as the level of media richness. On the other hand, others, such as Gunawardena (1995), have suggested that the level of social presence is determined by social factors, such as whether learners are familiar with each other.

These stances are extremes of one another. Spears, Postmes, Wolbert, Lea and Rogers (2000) suggested that social presence is established by a combination of technological and social factors. For example, not only the size of a webcam shot influences the level of social presence, but also whether the person who is shown is familiar. Further, if strangers talk about a subject that you find interesting, your feelings of social presence rise. In our study, it was assumed that social presence is based on both technological and social factors. Here, social presence was defined as the feeling of being aware of the other person in such a way that the other person seems real in the online communication (Kreijns et al., 2011).

\section{Aims and research questions}

To sum up, several gaps in the literature were found. First, hardly any studies have used observational techniques to explore feedback processes among teachers. Second, research has not yet addressed the role of social presence in these kinds of online feedback and social interaction processes. To address these gaps, this final study in our larger research project has two purposes. The first aim is to explore the coherence of observed and perceived feedback in the online learning environment; that is, whether student teachers who received more effective feedback also perceived this to be more effective than 
student teachers who received less effective feedback. The second aim is to explore how feelings of social presence are related to observed and perceived feedback.

To address the first goal of this study, feedback was viewed from two perspectives. First, provided online feedback was observed applying the theoretical notions described above. Second, perceptions of student teachers of that same online feedback were examined. These two perspectives were then combined and the first research question was formulated as follows:

- To what extent do observed feedback and perceived feedback cohere?

This study conceptualizes feedback as a social interaction process in which both receivers and providers provide feedback. In these interactions, coached teachers and peer coaches were part of the dimensions and peer coaches provided elements. It is suggested that this interaction process is influenced by feelings of social presence (Tu \& McIsaac, 2002). Therefore, it was expected that feelings of social presence positively affect feedback processes. To explore this, the second research question was formulated as follows:

- To what extent do social presence, observed feedback, and perceived feedback relate to each other?

\section{Method}

\section{Participants}

Sixteen student teachers from one Dutch teacher education institute participated (6 males; 10 females). They engaged in internships at secondary schools. The students were divided into five groups. In three of these groups, a teacher educator (all male) played the role of process supervisor. In the other groups, one of the student teachers (both male) was the process supervisor. These students also participated as coached teachers. Nine student teachers indicated their age in the questionnaires and their mean age was 47 years ( $\mathrm{sd}=7$ years). As such, this group of student teachers is representative of other Dutch student teachers in such teacher education programmes.

These student teachers all had other careers before they decided to become teachers. They followed a one year customized postgraduate teacher education course, which allows them, when graduated, to teach at the upper levels of secondary education. The course encompassed subjects on pedagogies and pedagogical content knowledge and internships. During these internships they were usually fully responsible for their subject. As such, the student teachers functioned as in-service teachers.

\section{Observations: Observed effective feedback}

To determine the quality and effectiveness of feedback, we used the Teacher Feedback Observation Scheme (TFOS; Thurlings, Vermeulen, Kreijns et al., 2012). The observations were conducted by the first author. In our pilot test of the TFOS, its inter-rater reliability was shown to be substantial (Thurlings, Vermeulen, Kreijns et al, 2012). Cohen's kappa ranged from 0.410 to 1.000 , averaging 0.756 . TFOS identifies the four feedback dimensions (i.e., goal-directedness, specificity, detailedness, and neutrality) and 12 feedback elements (e.g., open-ended questions, continuous questioning, and hinting). The scoring of these dimensions and elements in each utterance of coached student teachers and their peer coaches was done using Excel. For each feedback receiver, a new Excel file was used. Each column addressed a single dimension or element; the utterances were chronologically shown in the rows.

The procedure of scoring of the dimensions was executed as follows:

- When an utterance was completely goal-directed, we assigned a score of 4.

- When an utterance was completely non-goal/person-directed, we assigned a score of -4 .

- When an utterance was balanced between goal-directedness and non-goal/person-directedness, we assigned a score of 0 .

- Between these extremes ( +4 and -4$)$ and the zero-point, $a+2$ and $a-2$ can be assigned. 
This method resembled a Likert-type scale, such that the dimensions could be interpreted as continua. This method was also applied to the other dimensions (i.e. specificity, detailedness, and neutrality). The dimensions were scored in every utterance, including that of the coached teachers.

The feedback elements (e.g., closed questions, summarizing, and judging) were assigned either a 1 or a -1 , when the element respectively was expected to be effective (i.e., pushing the dimensions into the assumed effective directions) and ineffective (i.e., pushing the dimensions away from the assumed effective directions). The elements were scored if they occurred. Elements were mostly provided by peer coaches, however, if coached teachers provided an element, it was also scored.

Here, we provide an example from one of the sessions, in which the coached teacher wanted to improve her classroom management. In the fragment, the participants focus on how strict the coached teacher wants to be.

Peer coach: Yes, exactly. But you yourself, you say: I'm not that consistent. But I wish I were, if I could. But maybe being really, really strict does not fit you?

Feedback dimensions: goal-directedness: 4, specificity: 2, detailedness: 2, and neutrality: 0 .

Feedback elements: acknowledging, summarizing, continuous questioning.

Coached teacher: No, but that is what I do.

Feedback dimensions: goal-directedness: 2, specificity: -2, detailedness: -2, and neutrality: -2 .

Feedback elements: none.

Peer coach: Sometimes you just become angry and you expel the students right away. Do they expect that to happen, that they are expelled? Do they expect that at the moment that you do so?

Feedback dimensions: goal-directedness: 4, specificity: 2, detailedness: 2, and neutrality: 0 . Feedback elements: summarizing, continuous questioning.

Coached teacher: Well, they are not really surprised. But what I do notice, they just go on and on, until I get really angry. And they don't like it either, because if I say, next time, you're expelled, they usually get quieter. But then, they might start to say something else again, after that. So, I really should expel them, but I usually just don't.

Feedback dimensions: goal-directedness: 4, specificity: 2, detailedness: 2, and neutrality: 0 . Feedback elements: none.

\section{Questionnaire: Perceptions of feedback and feelings of social presence}

The questionnaire consisted of two parts. The first part aimed to evaluate perceived feedback and three subscales of the Assessment Experience Questionnaire (AEQ) were used (Gibbs \& Simpson, 2003). These subscales were chosen for several reasons. First, they are based upon Gibbs and Simpson's (2004) factors that support learning (see Section: How we defined effective perceived feedback in our studies). These factors additionally align with many other studies that have suggested similar aspects of feedback to be effective. Third, the questionnaire is generally reliable. The three subscales are quantity of feedback $(\alpha=0.58)$, quality of feedback $(\alpha=0.70)$, and what you do with the feedback $(\alpha=0.70)$. The items were restated to fit the peer coaching program, because the original items are focused on learning in school settings. We stayed as close as possible to the original wording. For instance, "On this course I get plenty of feedback on how I am doing" was reworded into "During the VIP meetings, I get plenty of feedback on my learning goals". Therefore, the respective numbers of the items of the scales were eight, six, and eight. The items were answered on a 5-point scale.

The second part of the questionnaire aimed to explore feelings of social presence (Short et al., 1976). The 21 items that assessed social presence are part of a pilot test that intends to develop a new questionnaire for determining the degree of social presence (Kreijns, Van Acker, Kirschner, Vermeulen \& Van Buuren, 2013). The social presence items focused on the realness of the other. In addition, the social presence scale reflects the view that social presence is determined by technological factors as well as by social factors. This questionnaire aligns with our notion of social presence. A sample item is: "I have the 
feeling of co-presence with my communication partners". The items yielded an alpha $(\alpha)$ of 0.922 and were answered on a seven-point scale.

\section{Procedure and data collection}

The online peer coaching program was introduced to the students during a face-to-face meeting at their teacher education institute. To facilitate the peer coaching sessions, Skype was used. The peer coaching sessions were recorded and transcribed. On average, the individual coaching sessions took 29 minutes, with a minimum of 16 minutes and a maximum of 50 minutes. Subsequently, TFOS was applied to the transcriptions. After the peer coaching sessions, the questionnaire was e-mailed to the students.

A complete set of data consisted of a recorded peer coaching session and an accompanying questionnaire from one coached student teacher. Such a complete set was needed to be able to address the research questions. From two groups, both meetings were recorded; from three groups, only one of the recordings of the meetings was collected, due to either technical issues or because the quality of the recording was too poor. In addition, some participants did not fill out the questionnaire. As a consequence, 10 complete sets of data of 8 participants were collected and analysed.

\section{Data analysis}

To answer the research questions, both qualitative and quantitative methods were used. In the qualitative approach, two case ordered descriptive meta-matrices (Miles \& Huberman, 1994) were constructed. Such a meta-matrix supports the ordering of the cases, here the 10 complete data sets, and from there on analyzing and interpreting the data. Before we could construct these meta-matrices, we needed data about the student teachers' perceptions (step 1) and about the observed feedback (step 2). In the first step, the descriptives for the results of the Assessment Experience Questionnaire (AEQ) subscales and the social presence scale were calculated. The second step is visualised in Figure 1. In this step, three benchmarks for effective observed feedback were established. These benchmarks are established in order to determine which participants received more effective feedback and which participants received less effective feedback compared to the average (i.e., the benchmark). The averages of effective feedback were constructed based on the observations in the 10 sets of data.

The first benchmark was called dimensions and included the average scores of the four feedback dimensions (i.e., goal-directedness, specificity, detailedness, and neutrality). The second benchmark was called ratio of elements and was the ratio of expected effective (e.g., open-ended questions and summarizing) versus expected ineffective (e.g., hinting and judging) feedback elements - expressed in percentages. The third benchmark was called ratio of effectiveness and expressed (a) the ratio of effectiveness of expected effective elements and (b) the ratio of expected ineffective elements - both in percentages. The difference between the second and third benchmark is that the second benchmark addressed the amount of feedback elements whereas the third benchmark attended to the effect of the elements on the dimensions.

To determine the ratios of effectiveness, timeline graphics depicting the dimensions and elements were created based on the Excel files; the x-axis depicted the chronological order of utterances, and the y-axis depicted the scoring of the dimensions and elements. The effectiveness of each feedback element (e.g., guiding questions, summarizing, and judging) was determined by comparing the positions of the dimensions on the timeline graphic in the utterances before and after the element occurred. If the dimensions were higher after the element than before, the element was counted as effective. If the dimensions were equal to or lower than before the element occurred, the element was counted as ineffective. By adding up the effectiveness of the elements, separately for expected effective and expected ineffective elements, the ratios of effectiveness were calculated.

Next, the first case ordered descriptive meta-matrix (Miles \& Huberman, 1994) was constructed. This meta-matrix was ordered based on the feedback perceptions. It depicted participants' individual scores on the questionnaire, starting with the lower than average scores and ending with the higher than average scores. 
The meta-matrix was then supplemented with participants' individual scores of the observed feedback compared to an average of effective feedback. These individual scores were expressed in L (lower than the average); A (average); and $\mathrm{H}$ (higher than the average) and were filled in the meta-matrix. This method provides insights into the effectiveness of each participant's observed feedback compared to the whole research group. In order to answer the first research question, it was explored whether the metamatrix could be broken down into groups of similar data.

In the qualitative approach of the second research question, a second case ordered descriptive meta-matrix was constructed (Miles \& Huberman, 1994), applying the same procedures as described above. This meta-matrix included the scores on the AEQ subscales, the social presence scale, and participants' individual scores compared to the three averages of effective feedback. Similar to the first meta-matrix, it was constructed based on the order of perceptions. Data on observed feedback and social presence was subsequently filled in. In order to answer the second research question, it was explored whether the metamatrix could be broken down into groups of similar data.

The quantitative approach consisted of calculating non-parametric Spearman correlation coefficients between social presence, the averages for observed feedback, and perceived feedback. Non-parametric Spearman correlation coefficients are the counterpart of parametric correlations and are used when the data does not meet the conditions for parametric tests.

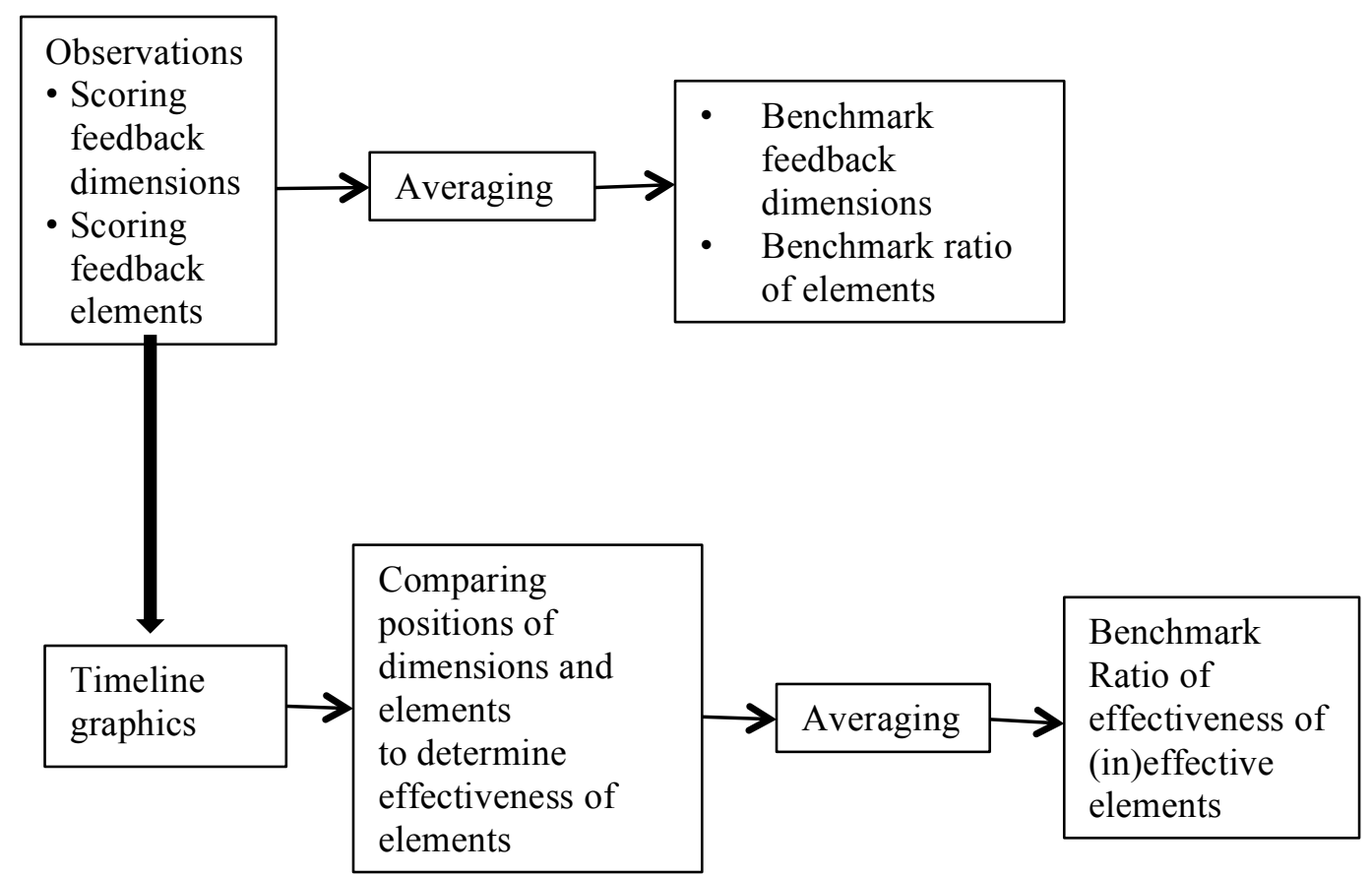

Figure 1. Visualization of the second step in the data-analysis.

\section{Results}

\section{The qualitative approach: Coherence of observed and perceived feedback}

Table 1 shows the descriptives for perceived feedback and feelings of social presence. The table shows that student teachers perceived feedback of good quantity and quality. Also, they generally intended to do something with the feedback they received. In addition, the student teachers generally felt their group members were real in the online communication. Table 1 also depicts the descriptives for the benchmark dimensions. The table shows that the dimensions were not highly pronounced. Feedback was mostly goaldirected, though not very specific. Also, a fair amount of feedback was detailed and mostly formulated in a neutral manner. 
Table 1

The descriptives of AEQ subscales $(n=10)$ and of feedback dimensions ( $n$ utterances $=966$ )

\begin{tabular}{lllll}
\hline & Mean & sd & minimum & maximum \\
\hline Questionnaires & & & & 4.75 \\
AEQ: Quantity of feedback & 4.18 & 0.39 & 3.50 & 5.00 \\
AEQ : Quality of feedback & 4.30 & 0.65 & 2.38 & 4.88 \\
AEQ : What you do with feedback & 4.41 & 0.77 & 4.43 & 6.19 \\
Social presence & 5.34 & 0.65 & & 2.53 \\
\hline Feedback dimensions & & & 0.65 & 1.11 \\
Goal- vs. non-goal-directedness & 1.53 & 0.70 & -0.17 & 1.40 \\
Specific vs. general & 0.48 & 0.40 & 0.34 & 0.58 \\
Detailed vs. non-detailed & 0.95 & 0.51 & 0.00 &
\end{tabular}

Note: The AEQ items were answered on a 5-point scale; the social presence items on a 7-point scale.

In the 966 utterances spoken in all coaching sessions, 511 expected effective feedback elements such as guiding questions and acknowledging, and 187 expected ineffective elements such as evocative questions and hinting were observed. Consequently, the ratio of expected effective and expected ineffective elements was 73:27.

Concerning the benchmark ratio of effectiveness, of all expected effective elements, $44 \%$ were indeed effective (i.e., pushing the dimensions into the assumed effective directions) and 56\% were not (i.e., pushing the dimensions away from the assumed effective directions). Of all expected ineffective elements $30 \%$ turned out to be effective and $70 \%$ were indeed ineffective.

Table 2 shows the first case ordered descriptive meta-matrix, which addresses the coherence between perceived and observed feedback. Note that the sequence of cases was made based on the AEQ, starting with the lower than average perceptions and ending with the higher than average perceptions. The individual scores on the ratio of elements and ratios of effectiveness seemed to follow the perceptions of feedback. More specifically, the list was broken down at two points, and therefore, three groups were discerned.

The first breakpoint was between Amy's second and her first session, where the ratio of elements changed from lower than average or average to higher than average. The second breakpoint was between Amy's first and Karin's second session. Not only was the ratio of elements more effective, but also the ratios of effectiveness.

In other words, the first group perceived feedback to be ineffective. This was also reflected in the observed feedback. They received more ineffective feedback elements, such as hinting and judging. These elements generally led the dimensions into the assumed ineffective directions: less goal-directed, more general, less detailed, and too negative or too positive. In addition, the expected effective elements they received generally led the dimensions into ineffective directions as well. The second group had more positive perceptions of the feedback they received. They generally received more expected effective elements than expected ineffective elements, yet the ratios of effectiveness of the elements were not to their advantage. The third group had higher than average perceptions of feedback. They, similar to the second group, received more expected effective elements than expected ineffective elements. In addition, the expected effective elements overall were indeed effective, pushing the dimensions into the effective directions, and the expected ineffective elements did, generally, not lead the dimensions away from these effective directions. 
Table 2

Results of the first cross-case meta-matrix

\begin{tabular}{|c|c|c|c|c|}
\hline Cases & AEQ & Average Dimensions & $\begin{array}{l}\text { Average } \\
\text { Ratio of } \\
\text { elements }\end{array}$ & $\begin{array}{l}\text { Average Ratio of } \\
\text { effectiveness }\end{array}$ \\
\hline
\end{tabular}

\begin{tabular}{|c|c|c|c|c|c|c|c|c|c|c|}
\hline & 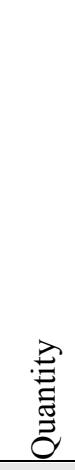 & 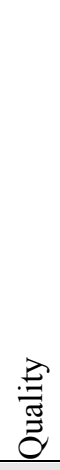 & 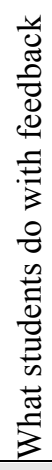 & 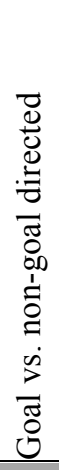 & 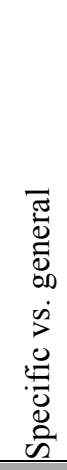 & 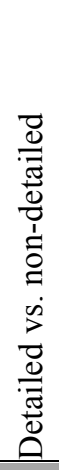 & 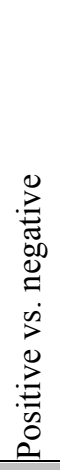 & 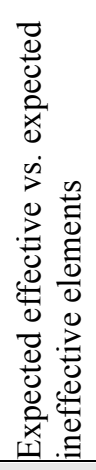 & 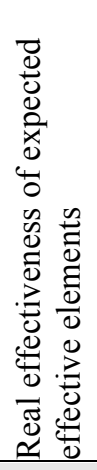 & 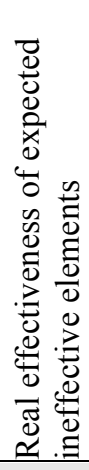 \\
\hline Douglas & $\mathrm{L}$ & $\mathrm{L}$ & $\mathrm{L}$ & $\mathrm{H}$ & $\mathrm{H}$ & $\mathrm{H}$ & A & $\mathrm{L}$ & $\mathrm{L}$ & L \\
\hline Liza & $\mathrm{L}$ & A & $\mathrm{L}$ & $\mathrm{H}$ & $\mathrm{H}$ & $\mathrm{H}$ & $\mathrm{L}$ & $\mathrm{L}$ & A & $\mathrm{L}$ \\
\hline Thomas & L & $\mathrm{L}$ & $\mathrm{H}$ & $\mathrm{H}$ & $\mathrm{H}$ & $\mathrm{H}$ & $\mathrm{L}$ & $\mathrm{L}$ & A & $\mathrm{H}$ \\
\hline Lauren & A & $\mathrm{L}$ & A & $\mathrm{L}$ & $\mathrm{L}$ & $\mathrm{L}$ & $\mathrm{L}$ & $\mathrm{H}$ & $\mathrm{L}$ & A \\
\hline Dean & A & $\mathrm{H}$ & A & $\mathrm{L}$ & $\mathrm{L}$ & $\mathrm{H}$ & A & $\mathrm{L}$ & A & A \\
\hline Amy2* & $\mathrm{L}$ & $\mathrm{H}$ & $\mathrm{H}$ & $\mathrm{H}$ & $\mathrm{H}$ & $\mathrm{H}$ & $\mathrm{H}$ & A & $\mathrm{L}$ & $\mathrm{L}$ \\
\hline Amy1* & $\mathrm{H}$ & $\mathrm{L}$ & $\mathrm{H}$ & $\mathrm{L}$ & $\mathrm{L}$ & $\mathrm{L}$ & $\mathrm{L}$ & $\mathrm{H}$ & $\mathrm{L}$ & $\mathrm{L}$ \\
\hline Karin2* & A & $\mathrm{H}$ & $\mathrm{H}$ & $\mathrm{H}$ & $\mathrm{H}$ & $\mathrm{H}$ & $\mathrm{L}$ & $\mathrm{H}$ & $\mathrm{H}$ & A \\
\hline Mary** & $\mathrm{H}$ & $\mathrm{H}$ & $\mathrm{H}$ & $\mathrm{L}$ & $\mathrm{H}$ & $\mathrm{L}$ & A & $\mathrm{H}$ & A & L \\
\hline Karin $1 *$ & $\mathrm{H}$ & $\mathrm{H}$ & $\mathrm{H}$ & $\mathrm{H}$ & $\mathrm{H}$ & $\mathrm{H}$ & $\mathrm{L}$ & $\mathrm{H}$ & $\mathrm{H}$ & $\mathrm{H}$ \\
\hline
\end{tabular}

Note: $\mathrm{L}=$ lower than the average, $\mathrm{A}=$ average, $\mathrm{H}=$ higher than the average

* Amy and Karin had two sessions and completed the questionnaire after both sessions.

** Mary did not receive any expected ineffective elements.

\section{The qualitative approach: Coherence of social presence, perceptions, and observed feedback}

Table 3 shows the second meta-matrix that incorporates social presence, feedback perceptions, and the participants' individual scores compared to the averages for received feedback. The order of cases resembles that of Table 2. Table 3 shows that participants who had higher than average feelings of social presence are at the upper half of the list and that participants who had lower than average feelings of social presence are on the lower half of the list.

This list was also broken down at two points, discerning three groups. The first breakpoint was between Amy's second session and Lauren, where the ratio of elements changed from lower than average or average to higher than average. The second breakpoint was between Amy's first and Karin's second session, where the average ratio of effectiveness changed from lower than average or average to higher than average. In other words, the three groups that were discerned here are similar to those discerned in the first meta-matrix. Parallel to the findings of Table 2, the dimensions seemed not to corroborate with the other findings.

Social presence seems to relate negatively to observed feedback: if higher feelings of social presence were perceived, the ratio of elements and ratios of effectiveness were lower than average. The quantitative approach provides more insights into this matter. 
Table 3

Results of the second cross case descriptive meta-matrix

\begin{tabular}{|c|c|c|c|c|c|c|c|c|c|c|c|}
\hline \multirow[t]{2}{*}{ Cases } & \multirow[b]{2}{*}{ 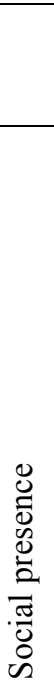 } & \multicolumn{3}{|c|}{ AEQ } & \multicolumn{4}{|c|}{ Average Dimensions } & $\begin{array}{l}\text { Average } \\
\text { Ratio of } \\
\text { elements }\end{array}$ & \multicolumn{2}{|c|}{$\begin{array}{c}\text { Average Ratio of } \\
\text { effectiveness }\end{array}$} \\
\hline & & 总 & 尝 & 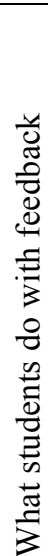 & 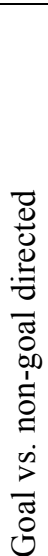 & 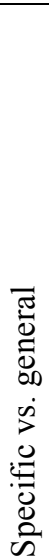 & 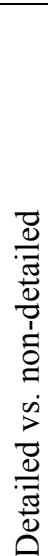 & 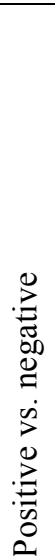 & 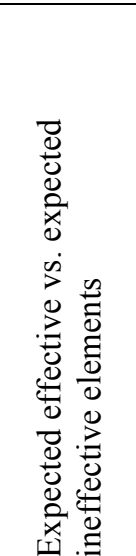 & 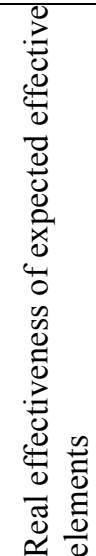 & 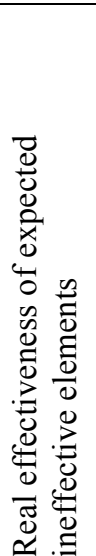 \\
\hline Douglas & $\mathrm{L}$ & $\mathrm{L}$ & $\mathrm{L}$ & $\mathrm{L}$ & $\mathrm{H}$ & $\mathrm{H}$ & $\overrightarrow{\mathrm{H}}$ & $\mathrm{A}$ & $\mathrm{L}$ & $\mathrm{L}$ & $\mathrm{L}$ \\
\hline Liza & $\mathrm{H}$ & $\mathrm{L}$ & A & $\mathrm{L}$ & $\mathrm{H}$ & $\mathrm{H}$ & $\mathrm{H}$ & $\mathrm{L}$ & $\mathrm{H}$ & A & $\mathrm{L}$ \\
\hline Dean & $\mathrm{H}$ & A & $\mathrm{H}$ & $\mathrm{A}$ & $\mathrm{L}$ & $\mathrm{L}$ & $\mathrm{H}$ & $\mathrm{A}$ & $\mathrm{L}$ & A & A \\
\hline Thomas & $\mathrm{H}$ & $\mathrm{L}$ & $\mathrm{L}$ & $\mathrm{H}$ & $\mathrm{H}$ & $\mathrm{H}$ & $\mathrm{H}$ & $\mathrm{L}$ & $\mathrm{L}$ & A & $\mathrm{H}$ \\
\hline Amy2* & $\mathrm{H}$ & $\mathrm{L}$ & $\mathrm{H}$ & $\mathrm{H}$ & $\mathrm{H}$ & $\mathrm{H}$ & $\mathrm{H}$ & $\mathrm{H}$ & A & $\mathrm{L}$ & $\mathrm{L}$ \\
\hline Lauren & $\mathrm{H}$ & A & $\mathrm{L}$ & A & $\mathrm{L}$ & $\mathrm{L}$ & $\mathrm{L}$ & A & $\mathrm{H}$ & $\mathrm{L}$ & A \\
\hline Amy1* & A & $\mathrm{H}$ & $\mathrm{L}$ & $\mathrm{H}$ & $\mathrm{L}$ & $\mathrm{L}$ & $\mathrm{L}$ & $\mathrm{L}$ & $\mathrm{H}$ & $\mathrm{L}$ & $\mathrm{L}$ \\
\hline Karin $2 *$ & $\mathrm{~L}$ & A & $\mathrm{H}$ & $\mathrm{H}$ & $\mathrm{H}$ & $\mathrm{H}$ & $\mathrm{H}$ & $\mathrm{L}$ & $\mathrm{H}$ & $\mathrm{H}$ & A \\
\hline Karin $1 *$ & $\mathrm{~L}$ & $\mathrm{H}$ & $\mathrm{H}$ & $\mathrm{H}$ & $\mathrm{H}$ & $\mathrm{H}$ & $\mathrm{H}$ & $\mathrm{L}$ & $\mathrm{H}$ & $\mathrm{H}$ & $\mathrm{H}$ \\
\hline Mary** & $\mathrm{L}$ & $\mathrm{H}$ & $\mathrm{H}$ & $\mathrm{H}$ & $\mathrm{L}$ & $\mathrm{H}$ & $\mathrm{L}$ & $\mathrm{A}$ & $\mathrm{H}$ & A & $\mathrm{L}$ \\
\hline
\end{tabular}

Note: $\mathrm{L}=$ lower than the average, $\mathrm{A}=$ average, $\mathrm{H}=$ higher than the average

* Amy and Karin had two sessions and completed the questionnaire after both sessions.

** Mary did not receive any expected ineffective elements.

\section{The quantitative approach: Social presence, observed feedback, and feedback perceptions}

Spearman correlation coefficients were calculated in order to investigate relationships between the observation and questionnaire findings, approaching the research questions in a quantitative manner. Here we discuss those correlations that were significant. Feelings of social presence negatively correlated with perceptions of feedback quantity $\left(r_{s}=-0.508, p=0.134\right)$. This suggests that more feelings of the others in the online communication led to less satisfaction with feedback quantity.

The feedback dimension detail had four significant correlations. First, it correlated negatively with perceptions of feedback quantity $\left(r_{s}=-0.771, p=0.009\right)$. This suggests that feedback that contained many details led student teachers to believe that feedback was of less quantity. Second, the dimension detailedness correlated negatively with what student teachers perceived they would do with feedback $\left(r_{s}=\right.$ $-0.485, p=0.156)$. This indicates that if student teachers receive many detailed feedback utterances they are less inclined to act on it. Perhaps too many suggestions were put forward and the student teachers became overwhelmed. Third, the dimension detailedness correlated positively with the dimension goaldirectedness $\left(r_{s}=0.479, p=0.162\right)$, and fourth with the dimension specificity $\left(r_{s}=0.503, p=0.138\right)$. This suggests that more detailed feedback also led to more goal-directed feedback and to more specified feedback.

The ratio of feedback elements correlated significantly with four other variables. First, it negatively correlated with feelings of social presence $\left(r_{s}=-0.600, p=0.067\right)$. This suggests that if participants received more feedback elements, they felt the others were less real in the online communication. 
Second, the ratio of feedback elements correlated positively with perceptions of feedback quantity $\left(r_{s}=\right.$ $0.869, p=0.001)$. This indicates that if more feedback elements were provided, the receivers perceived feedback of better quantity. Third, the ratio of feedback elements correlated positively with what student teachers perceived they would do with the received feedback $\left(r_{s}=0.485, p=0.156\right)$. This suggests that if student teachers received more feedback elements, they were more inclined to act on the feedback. Fourth, the ratio of elements correlated negatively with the dimension of detailedness $\left(r_{s}=-0.842, p=\right.$ 0.002). This indicates that when more feedback elements were provided, feedback became less detailed.

The ratio of effectiveness of expected effective elements correlated significantly with three other variables. First, it correlated positively with perceptions of feedback quality $\left(r_{s}=0.554, p=0.097\right)$. This indicates that if expected effective elements indeed pushed the dimensions into the assumed effective directions, student teachers were more satisfied with the feedback quality. Second, the ratio of effectiveness of expected effective elements correlated positively with the dimension of specificity $\left(r_{s}=\right.$ $0.571, p=0.084)$. This indicates that if expected effective elements pushed the dimensions into the assumed effective directions, feedback indeed became more specific. Third, the ratio of effectiveness of expected effective elements correlated negatively with the dimension neutrality $\left(r_{s}=-0.771, p=0.021\right)$. This suggests that if expected effective elements pushed the dimensions into the assumed effective directions, feedback became less positive, more neutral or even negative. This might be confusing, because the dimension neutrality is different from the others. Here, the neutral position (assigned score of 0 ) is considered effective, while too positive (assigned score of +4 ) or too negative (assigned score of -4 ) are considered ineffective. In other words, for feedback to be neutral, expected effective elements need to be ineffective.

The ratio of effectiveness of expected ineffective elements correlated significantly with two variables. First, it correlated negatively with the dimension neutrality $\left(r_{s}=-0.512, p=0.130\right)$. This indicates that if expected ineffective elements pushed the dimensions into the assumed effective directions - as opposed to the expectations - feedback became more neutral, or even negative. Similar to the last correlation described in the former paragraph, expected ineffective elements need to be ineffective for feedback to become neutral. Second, the ratio of effectiveness of expected ineffective elements correlated positively with the ratio of effectiveness of expected effective elements $\left(r_{s}=0.511, p=0.131\right)$. This indicates that if expected ineffective elements pushed the dimensions into the assumed effective directions, expected effective elements also pushed the dimensions into the assumed effective directions.

The finding that social presence related negatively to all feedback perceptions implied that higher feelings of social presence did not lead to higher perceptions. These findings contradicted the expectations. A thorough analysis of Spearman's correlations at the item level provided a more nuanced view. Higher feelings of the other people's presence, for instance, led student teachers to be more inclined to listen to feedback, feel that feedback was provided in time, and feel more support to improve and reflect on the formulation of their goals and actions. In addition, if student teachers thought that they were present in the perception of the others, they were more willing to improve their actions. These findings were in alignment with the expectations.

An exception to these findings was that if student teachers thought the others could feel their presence, the feedback perceptions became lower. Maybe feeling their presence crossed a boundary, suggesting that the student teachers felt as if the others were too close,. Other correlations at the item level showed that if student teachers felt nobody was listening, they did not feel supported and felt feedback that aids to improve their actions lacked. These findings supported the expectations, yet they took a reversed perspective: lower feelings of social presence led to lower feedback perceptions.

Some examples of these significant correlations at the item level are provided in Table 4. The first two rows show the findings that were in alignment with the expectations, the third row addresses the exception, and the final row attends the reversed findings. 
Table 4

Examples of significant Spearman's correlation coefficient at the item level of the AEQ subscales and the social presence scale $(n=10)$

\begin{tabular}{|c|c|c|}
\hline Item social presence & Item AEQ & $\begin{array}{l}\text { Spearman's } \\
\text { correlation } \\
\text { coefficient }\end{array}$ \\
\hline $\begin{array}{l}\text { I feel that my communicating partners are } \\
\text { 'real' physical persons }\end{array}$ & $\begin{array}{l}\text { Whatever feedback I get comes too late } \\
\text { to be useful }\end{array}$ & $0.648 *$ \\
\hline $\begin{array}{l}\text { I think that my communication partners } \\
\text { feel that I am a 'real' physical person }\end{array}$ & $\begin{array}{l}\text { The feedback does not help me to } \\
\text { formulate new goals }\end{array}$ & $0.648 *$ \\
\hline $\begin{array}{l}\text { I think that my communication partners } \\
\text { can feel my presence }\end{array}$ & The feedback comes back very quickly & $-0.679 *$ \\
\hline $\begin{array}{l}\text { I feel that my messages are absorbed in a } \\
\text { huge empty space }\end{array}$ & $\begin{array}{l}\text { If my learning goal is not formulated } \\
\text { specifically enough, I don't receive } \\
\text { much guidance in what to do about it }\end{array}$ & $-0.714 *$ \\
\hline
\end{tabular}

Note: Negatively formulated items were reversed before correlations were calculated.

* Significant at $p$-value $<0.05$

\section{Discussion}

In this final empirical study of our research project, we focused on the interplay of observed and perceived feedback and feelings of social presence. In a naturalistic setting, peer feedback of student teachers engaging in synchronous online peer coaching was observed and they filled in questionnaires that sought their perceptions of provided feedback and social presence.

A first conclusion is that coherence of feedback observations and feedback perceptions exists in synchronous online peer coaching by student teachers. Those student teachers that received more effective feedback - goal-directed, specific, detailed, and neutral that was promoted by feedback elements - believed this feedback was of better quality and quantity than participants who received less effective feedback - non-goal-directed, general, non-detailed, and too positive or too negative. This finding was also revealed in our former study (Thurlings, Vermeulen, Bastiaens \& Stijnen, 2012), in which 12 primary school teachers applied the same peer coaching program, yet in face-to-face settings. These findings combined, suggest that the coherence of observed and perceived feedback exists in both online and face-to-face settings and that feedback processes develop in a same way in these settings.

The study described in this paper and the former study thus show that the theoretical notions about what effective feedback is are supported by feedback perceptions. Feedback that is goal-directed, specific, detailed, and neutral is perceived as more effective than feedback that is non-goal-directed, general, nondetailed, and too positive or too negative. To support feedback receivers to become and remain goaldirected, specific, detailed, and neutral, peer coaches have to provide those feedback elements that were shown to do so: open-ended, guiding, and solution-focused questions, and continuous questioning after summarizing. Hinting, judging, evocative questions, and elaborating on one's own experience is best avoided. Consequently, feedback becomes a dialogue (see also Licklider, 1995), where teachers acknowledge, respect, and listen to each other. When the peer coaching program is used in schools, it is therefore important that the coaching styles it proposes (i.e., solution-focused thinking) are used by peer coaches and process supervisors. These coaching styles were shown to have positive effect on the provided and perceived feedback.

The scores on the feedback dimensions were fuzzy and seemed to not corroborate with these findings in the recent study. Feedback receivers were part of the dimensions themselves, as well the feedback providers. The feedback elements however were almost in all cases provided by the feedback providers. Perhaps feedback elements are perceived as an impulse, and give directions to the effectiveness of observed feedback and to the perceptions of that same feedback.

A second conclusion is that social presence influences these feedback processes. The overall finding that the social presence scale related negatively to feedback perceptions contradicted the expectations. 
However, a closer examination of correlations at the item level demonstrated a more nuanced view. These results imply that the social presence scale holds different subscales, which should be treated as such in the data analysis. Due to a small sample, techniques like factor analysis could not be performed and a larger sample is needed.

Feelings of social presence only related significantly to one of the observed feedback averages, namely the ratio of expected effective and expected ineffective elements. This showed that if more expected effective elements were provided, feelings of social presence were less high. Since social presence is believed to play an important role in online social interaction and learning (Tu \& McIsaac, 2002), feedback processes might explain this relation. Feedback is a social event and related to learning (Hattie \& Timperley, 2007); social presence as well. This study provided preliminary results on these relations and calls for more research that further examines these relations with more participants.

The findings of our studies seem to suggest that online synchronous feedback processes are similar to face-to-face feedback processes. This indicates that in practice, online synchronous feedback can be as effective as face-to-face feedback. Moreover, this study suggests that teacher professional development activities can be reinforced by applying ICT tools that allow teachers to provide each other with effective feedback. Because effective feedback is known to positively affect learning (Hattie \& Timperley, 2007), this might even suggest that such ICT tools can enhance teachers' learning.

Former studies have also shone a light on online learning for teachers. Nandi et al. (2012) for instance focused on the quality of asynchronous online discussion forums and the role of the instructor. They showed that students interact in the online discussion forums: they provide new ideas, react to each other's messages, and critically think about the subjects at hand. Instructors were shown to have a large influence on these processes. In our study, the student teachers were supposed to be guided by process supervisors, yet in some groups such a facilitator was also a participant in the peer coaching. Similarly, many studies have focused on the role of an instructor or moderator in online learning processes. For instance, Helleve (2007) showed that such a person is an important factor in the success of online learning and collaboration. Moreover, Dorner (2012) showed that the style of moderation influences the interaction process. In smaller groups, moderation tended to be more directive than facilitative, however, Dorner's (2012) findings also indicated that a facilitative style led to more cognitive engagement, such as more analytical messages from the participating teachers. Likewise, Chen, Chen, and Tsai (2009) demonstrated that moderators influence the way (student) teachers interact and discuss online. Our other studies have also shown the importance of such an instructor or facilitator (Thurlings, Vermeulen, Kreijns et al., 2012). These findings once again strongly suggest that for online learning to succeed, whether synchronously or asynchronously, a good facilitator is a necessity.

There are some limitations of the study. First, the TFOS does not focus on aspects such as trust and credibility, which are considered to influence feedback processes (Ilgen, Fisher \& Taylor, 1979). Several recent studies indeed showed that trust among the participants influences the success of student teachers collaborating online (Helleve, 2007). Indications of the influence of such factors were revealed in our studies, but it might be worthwhile to explore this issue more systematically. In addition, the study examined the interaction between receivers, providers, and feedback messages, which is a major part of feedback processes. Learning outcomes were not addressed in our studies, because the feedback processes were studied in depth. Finally, each group of student teachers had a different process supervisor, and in some groups a student teacher was both a process supervisor and a coached teacher. The number of participants in our study was too small to control for this aspect.

Future research could look into the role of the process supervisor in online learning and teacher professional development. What makes a good process supervisor? Another suggestion is to include data on the (student) teachers' behaviour in their classrooms and relate this to feedback processes. Does effective feedback indeed lead to an improvement in teaching behaviour? In future research, we could also adapt our instruments and elaborate on aspects such as trust and credibility. A final suggestion would be to explore the role of social presence in online feedback processes among (student) teachers. Though we have found indications that social presence influences online feedback processes, future research is needed to make more evidence-based claims on this matter. 
Online learning is expanding and will more and more be part of education and professional development activities. In online learning, feedback does play a significant part, perhaps the most important part. In addition, feelings of social presence also play their significant part. Our knowledge of how these processes are most beneficial for learners is still in development, however, we now have a foundation for how feedback and social presence can be used in future research and to further optimize these processes to support learning in educational practice.

\section{References}

Black, P., \& Wiliam, D. (1998). Assessment and classroom learning. Assessment in Education: Principles, Policy \& Practice, 5(1), 7-68. doi:10.1080/0969595980050102

Caballé, S., Daradoumis, T., Xhafa, F., \& Juan, A. (2011). Providing effective feedback, monitoring and evaluation to on-line collaborative learning discussions. Computers in Human Behavior, 27(4), 1372 1381.

Chen, Y., Chen, N.-S., \& Tsai, C.-C. (2009). The use of online synchronous discussion for web-based professional development for teachers. Computers \& Education, 53(4), 1155-1166.

Colasante, M. (2011). Using video annotation to reflect on and evaluate physical education pre-service teaching practice. Australasian Journal of Educational Technology, 27(1), 66-88.

Collins, A., \& Halverson, R. (2009). Rethinking education in the age of technology: The digital revolution and schooling in America. New York: Teachers College Press.

Daft, R. L., Lengel, R. H., \& Trevino, L. (1987). Message equivocality, media selection, and manager performance. MIS Quarterly. Retrieved from http://www.jstor.org/stable/248682

Dorner, H. (2012). Effects of online mentoring in computer-supported collaborative learning environments: Mentor presence and cognitive engagement. American Journal of Distance, 26(3), 157-171.

Entwistle, N. J. (1991). Approaches to learning and perceptions of the learning environment: Introduction to special issue. Higher Education, 22, 201-204. doi:10.1007/BF00132287

Geister, S., Konradt, U., \& Hertel, G. (2006). Effects of process feedback on motivation, satisfaction, and performance in virtual teams. Small Group Research, 37(5), 459-489.

Gibbs, G., \& Simpson, C. (2003, September). Measuring the response of students to assessment: The assessment experience questionnaire. Paper presented at The International Improving Student Learning Symposium, Hinckley, UK.

Gibbs, G., \& Simpson, C. (2004). Conditions under which assessment supports students' learning. Learning and Teaching in Higher Education, 1, 3-31.

Gunawardena, C. N. (1995). Social presence theory and implications for interaction and collaborative learning in computer conferences. International Journal of educational Telecommunications, 1(2\&3), 147-166.

Hattie, J.,\& Timperley, H. (2007). The power of feedback. Review of Educational Research, 77(1), 81112.

Helleve, I. (2007). In an ICT-based teacher-education context: Why was our group "the magic group"? European Journal of Teacher Education, 30(3), 267-284.

Hyland, K., \& Hyland, F. (2006). Feedback on second language students' writing. Language Teaching, 39, 83-101.

Ilgen, D. R., Fisher, C. D., \& Taylor, M. S. (1979). Consequences of individual feedback on behavior in organizations. Journal of Applied Psychology, 64(4), 349-371. doi:10.1037/0021-9010.64.4.349

Jackson, P., \& McKergow, M. (2002). Oplossingsgericht denken [Solution-focused thinking]. Zaltbommel, the Netherlands: Thema.

Jeninga, J. (2003). Peer coaching: "Van en met elkaar leren" als krachtig leermiddel ter bevordering van integrale leerlingbegeleiding en schoolontwikkeling [Peer coaching: "Learning from and with each other" as powerful learning tool to promote integrated student counseling. In J. Fanchamps \& J. van der Sanden (Eds.), Integraal ondersteunen van een vernieuwd VMBO [Integrated support of renewed secondary vocational education] (pp. 25-32). Antwerpen, Belgium: Garant.

King, K. P., \& Dunham, M. D. (2005). Finding our way: Better understanding the needs and motivations of teachers in online learning. International Journal of Instructional Technology and Distance Learning, 2, 11-26.

Kreijns, K., Kirschner, P. A., Jochems, W., \& van Buuren, H. (2011). Measuring perceived social presence in distributed learning groups. Education and Information Technologies, 16(4), 365-381. 
Kreijns, K., Van Acker, F., Kirschner, P. A., Vermeulen, M., \& van Buuren, H. (2013, August). Supporting social interaction for group dynamics through social affordances in CSCL: Group awareness widgets.Paper presented at The 10th European Conference for Research on Learning and Instruction (EARLI), Padova, Italy.

Licklider, B. L. (1995). The effects of peer coaching cycles on teacher use of a complex teaching skill and teachers' sense of efficacy. Journal of Personal Evaluation in Education, 9, 55-68.

Miles, M. B., \& Huberman, A. M. (1994). Qualitative data analysis. (2nd ed.). Thousand Oakes: SAGE.

Mory, E. H. (2003). Feedback research revisited. In D. H. Jonassen (Ed.), Handbook of research for educational communications and technology (pp. 745-783). New York: MacMillan Library Reference.

Nandi, D., Hamilton, M., Chang, S., \& Balbo, S. (2012). Evaluating quality in online asynchronous interactions between students and discussion facilitators. Australasian Journal of Educational Technology, 28(4), 684-702.

Östlund, B. (2008). Prerequisites for interactive learning in distance education: Perspectives from Swedish students. Australian Journal of Educational Technology, 24(1), 42-56.

Scheeler, M. C., Ruhl, K. L., \& McAfee, M. K. (2004). Providing performance feedback to teachers: A review. Teacher Education and Special Education, 27(4), 396-407.

Scouller, K. (1998). The influence of assessment method on students' learning approaches: Multiple choice question examination versus assignment essay. Higher Education, 35(4), 453-472.

Segers, M., Gijbels, D., \& Thurlings, M. (2008). The relationship between students' perceptions of portfolio assessment practice and their approaches to learning. Educational Studies, 34(1), 35-44.

Short, J., Williams, E., \& Christie, B. (1976). The social psychology of telecommunications. London: John Wiley \& Sons, Ltd.

Smith, P. L., \& Ragan, T. J. (1993). Designing instructional feedback for different learning outcomes. In J. V Dempsey \& G. C. Sales (Eds.), Interactive instruction and feedback (pp. 75-103). Englewoods Cliffs, NJ: Educational Technology.

Spears, R., Postmes, T., Wolbert, A., Lea, M., \& Rogers, P. (2000). Social psychological influence of ICT on society and their policy implications (Electronic version). Amsterdam: Infodrome. Retrieved from http://numerons.files.wordpress.com/2012/04/2social-psychological-influence-of-ict.pdf

Thurlings, M., Vermeulen, M., Bastiaens, Th., \& Stijnen, P. (2012). Investigating feedback among teachers: Coherence of observed and perceived feedback. Mentoring and Tutoring, 20(4), 473-490.

Thurlings, M. \& Vermeulen, M., Bastiaens, Th., \& Stijnen, P. (2013). Understanding feedback: A learning theory perspective. Educational Research Review, 9(1), 1-15.

Thurlings, M., Vermeulen, M., Kreijns, K., Bastiaens, Th., \& Stijnen, P. (2012). Development of the Teacher Feedback Observation Scheme: Evaluating the quality of feedback in peer groups. Journal of Education for Teaching, 38(2), 193-208.

Tsai, I. (2012). Understanding social nature of an online community of practice for learning to teach. Educational Technology \& Society, 15(2), 271-285.

Tu, C. H., \& McIsaac, M. (2002). An examination of social presence to increase interaction in online classes. American Journal of Distance Education, 16(3), 131-150.

Wenger, E., \& Snyder, W. M. (2000). Communities of practice: The organizational frontier. Harvard Business Review, 78(1), 139-145.

Yang, S. C., \& Liu, S. F. (2004). Case study of online workshop for the professional development of teachers. Computers in Human Behavior, 20(6), 733-761.

Corresponding author: Marieke Thurlings, m.c.g.thurlings@tue.nl

Australasian Journal of Educational Technology (C) 2014.

Please cite as: Thurlings, M., Vermeulen, M., Bastiaens, T., \& Stijnen, S. (2014). The role of feedback and social presence in an online peer coaching program for student teachers. Australasian Journal of Educational Technology, 30(3), 326-341. 